HIV/AIDS

\section{HIV/AIDS prevention in Uganda: why has it worked?}

\section{S J Genuis, S K Genuis}

\section{HIV/AIDS prevention}

$\mathrm{T}$ he World Health Organisation's 2004 report Changing History describes the HIV/AIDS pandemic as "the world's leading public health challenge" and anticipates catastrophic social and economic consequences in many developing countries. ${ }^{1}$ This infection, the leading cause of death among 15 to 59 year olds worldwide ${ }^{1}$ and the second leading cause of serious sickness and disability in the world, ${ }^{2}$ infects an estimated 14000 people each day. In noticeable contrast with escalating HIV rates in many nations, a unique programme in Uganda, one of the nations worst hit by the HIV epidemic, has resulted in a profound decline in national HIV seroprevalence from reported rates as high as $30 \%$ in the early $1990 \mathrm{~s}^{3}{ }^{4}$-the highest in the world at the time ${ }^{4}$ - to an estimated $5 \%$ in $2001 .^{5}$ Given the proportions of the global HIV/AIDS pandemic, a public health crisis that is only in its early phases, ${ }^{6}$ many organisations and groups have endeavoured to explicate factors contributing to the national success of Uganda's strategy.

In the late 1980s, when the sequelae of rising HIV rates were becoming increasingly evident, public health programmes tackling HIV/AIDS were started. The strategy of risk reduction through the promotion of barrier protection became the mainstay of most behavioural interventions. Uganda, however, "went against the current"7 and chose an adaptable strategy that was designed to target all segments of the population through an "ABC" approach to sexual behaviour change: delayed sexual debut for youth (A, abstinence), partner reduction for the sexually active (B, be faithful), and factual information regarding condom use for those who were infected or involved in risky lifestyles (C, condoms). ${ }^{58}$ The recent recognition of the remarkable diminution in HIV/AIDS in Uganda at a time of escalating rates of HIV seroprevalence in neighbouring countries $^{5}$ has led to intense debate and discussion about specific determinants accounting for the remarkable decline in this infectious illness.
Conclusions drawn from this discussion have been varied and even contradictory: some conclude that promotion of delayed sexual debut was a pivotal factor in HIV reduction, ${ }^{510}$ while others claim that partner reduction was the lever that changed the course of history for Uganda'; some suggest that increased barrier protection is responsible for progress in the war against HIV, ${ }^{11}$ while others say that success is attributable to injection safety resulting from cleaner needles ${ }^{12}$; and yet others deny the extent of HIV/AIDS decline claiming that reported HIV rates were inaccurate ${ }^{13}$ or that there is statistical misinterpretation because AIDS mortality has resulted in decreased seroprevalence. ${ }^{11}$

Discussion of the Ugandan success story has recently evoked much passion, but a major loser in this imbroglio may be medical science. Any discussion of sexual behaviour inherently entails strongly held beliefs; therefore, carefully accumulated data published in the peer review literature over the past few years $^{58914}$ may be in danger of being trumped by philosophical perspectives, economic interests, and sexual ideology. The net result of apparently conflicting and mutually exclusive claims relating to the AIDS situation in Uganda is serious: confusion regarding determinants of the declining HIV seroprevalence data has the potential to paralyse forward action in the HIV/AIDS crisis. Observers and public policy makers must resolve the current tension of conflicting information by careful anaing, and deductive reasoning. To apply such analysis, primary principles of scientific scrutiny should be invoked.

\section{SCIENTIFIC SCRUTINY OF CONFLICTING CLAIMS}

Firstly, application of fundamental inquiry to hypotheses, results, and conclusions is in order. Basic questions should be clarified, including: (a) what factors are unique in the Ugandan programme relative to other nations?; (b) if HIV decline is attributable predominantly to condom promotion, why lysis of evidence, critical scientific think- are surrounding countries that have higher rates of condom sales and condom use experiencing escalating rates of HIV?; and, (c) if delayed sexual debut and partner reduction are not factors in success, why has Uganda's president, many of the health officials, and various scientific papers attributed the success to these factors?.

Secondly, an important element of scientific inquiry is reproducibility. For example, data from other nations instituting programmes incorporating sexual behaviour change through partner reduction show similar trends as Uganda of declining STD rates, ${ }^{8}{ }^{15}$ while condomcentric programmes have not met with desired objectives in most nations. ${ }^{16}$

Thirdly, it is vital to examine and understand the normal cycle of information generation, which generally moves from presentation of preliminary results at meetings and conferences through to detailed analysis, peer review, and potential publication. This is of particular concern as premature dissemination of preliminary information presented at a well publicised conference meeting has recently been used to refute high quality existing evidence about the $\mathrm{ABC}$ initiative. ${ }^{17}$

\section{SCIENTIFIC VALIDITY OF CONFERENCE PROCEEDINGS}

In the Journal of the American Medical Association, Schwarz et al report that despite the fact that papers presented at conferences and meetings are usually just beginning the process of scientific scrutiny, "abstracts at scientific meetings receive substantial attention in the high-profile media." ${ }^{18}$ Furthermore, press releases often "exaggerate the perceived importance of findings"19 and rarely highlight study limitations or conflicts of interest. A clear illustration is provided by conference reporting of the sequelae of hormone use. With the Women's Health Initiative (WHI) finding that long term hormone replacement therapy (HRT) posed more risk than benefit for menopausal women, ${ }^{20} 21$ concern has mounted about potential dangers associated with oral contraceptives, agents containing significantly higher doses of oestrogen relative to HRT. At the 2004 American Society for Reproductive Medicine's annual scientific conference, a presentation was made, based on WHI generated data, that suggested oral contraceptives users are less likely to develop cardiovascular disease. ${ }^{22}$ After worldwide media attention, the director of the WHI released a definitive statement through the US Department of Health and Human Services $^{23}$ stating that the presenting group had "flaws in both the design 
and interpretation." ${ }^{23}$ This latter corrective statement, however, was not reported extensively in the media; as a result, many doctors and consumers may have been left with a false perception of evidence related to hormone use.

A recent conference presentation, ${ }^{17}$ which endeavoured to interpret HIV decline in Uganda, has also received worldwide media coverage. This presentation discussed recent data and concluded that condom use and AIDS mortality were primarily responsible for declining HIV in Uganda, apparently disregarding previous presented evidence showing that delayed sexual debut and monogamy were pivotal factors. ' Without prior evaluation by the scientific community, without disclosure of conflicts of interest, and without reporting on study limitations, headlines such as "Abstinence programmes do not reduce HIV prevalence in Uganda"11 or "Condom use and deaths explain lower HIV prevalence" ${ }^{\prime 24}$ appeared in medical journals, on physician information web sites, and in periodicals throughout the world, thus obscuring the issue of HIV decline in Uganda and potentially impairing forward movement to tackle the pandemic.

Review of the presented data, however, suggests that there are serious concerns related to the scientific interpretation of this abstract. For example, the locally devised $\mathrm{ABC}$ programme in Uganda was developed in 1986 and most of the decline in HIV incidence occurred from the late 1980s to about 1994; Wawer et al's abstract reflects data collected from 1994 to 2003, a time period that followed the major decline in HIV incidence. As well, basic epidemiological principles show that mortality is the primary means for prevalence reduction in chronic disease including HIV/AIDS; mortality rates do not explain the aetiology of declining HIV incidence between 1986 and 1994, nor do they explain the lower HIV seroprevalence relative to other nations with higher rates of condom use. Furthermore, the recent increase in sexual risk taking behaviour (including a decline in abstinence and increase in multiple partners) since 1994 as well as the increased use of condoms-as discussed in the conference presentationcoincides with the recent increase in foreign sex education programmes that emphasise condom use and minimise the original $\mathrm{ABC}$ approach of the Ugandan administration. ${ }^{25}$ Dr Edward Green, a research scientist at Harvard recently commented, "the unique indigenous program that Uganda developed is being gradually destroyed... infection rates will start going up again and then experts will say $\mathrm{ABC}$ never worked." ${ }^{25}$ It is evident that scientific queries regarding this presentation abstract need to be addressed before adoption of conclusions into policy design. Furthermore, a call for clarity is in order as the scientific community must remain fully cognisant of the relative significance of various stages of the information cycle and responsibly transmit scientific information to the consuming public.

At a time of exploding and spreading rates of HIV and other STDs throughout many areas of the world, ${ }^{16}$ what is unique in the original Ugandan model that allowed incidence rates of HIV to decline so precipitously? Our analysis of the situation in Uganda leads us to believe that the success of this programme can be attributed to three broad based principles: (1) HIV/AIDS was openly addressed; (2) sexual behaviour change was specifically targeted; and (3) the programme was adaptable across population groups.

\section{OPEN ACKNOWLEDGMENT OF PROBLEM}

Beginning in 1986, the devastating impact of HIV/AIDS was acknowledged at the highest level of government in Uganda and prevention programmes were established across governmental ministries and non-governmental organisations. Ongoing, candid public media campaigns ensued and "community mobilization for a grass-roots offensive against HIV"'5 occurred. Information and a call for fundamental behaviour change was communicated by both health workers and influential people from a range of local community groups. While high level political support was fundamental, personal communication networks in both urban and rural settings "predominated in communicating about AIDS." ${ }^{\prime 9}$ Furthermore, it is these personal and community networks that are credited as being critical "to bridge the motivational gap between AIDS prevention activities and behaviour change sufficient to affect HIV incidence." ${ }^{5}$ Open acknowledgement of the pandemic had the following results: in contrast with some other nations where myths and denial has contributed to confusion about HIV/ AIDS, Ugandans were highly likely to report personal knowledge of someone who had or had died of AIDS ${ }^{\text {; }}$ knowledge of public figures with AIDS has led to "a remarkably accepting and nondiscriminatory response to AIDS" ${ }^{\prime \prime}$; and the concept of "prevention-to-care" resulted in a community based approach to caring for people living with HIV/ AIDS. $^{5}$

\section{TARGETING SEXUAL BEHAVIOUR CHANGE}

Recognising that most HIV infection occurred through consensual sexual acts and that national HIV/AIDS rates might be affected if population level change in risk taking behaviours was mobilised, ${ }^{9}$ the Ugandan government introduced an ABC approach to sexual behaviour change. This model, which provided direct advice to specific populations on HIV/AIDS avoidance through behaviour change, was promoted as a "patriotic duty". ${ }^{\prime}$ Steering clear of a focus on "values", this approach unapologetically recommended the promotion of health through delayed sexual debut for adolescents and partner reduction for the sexually active. ${ }^{8}$ Subsequent analysis of HIV surveillance and behavioural data confirms that these were the pivotal factors in reducing HIV incidence in Uganda and, furthermore, that a population wide reduction in casual sex "reduced the size of high-risk sexual networks and the efficiency of HIV transmission". ${ }^{5}$ Targeted promotion of sexual behaviour change in the form of direct education about consistent condom use for those already infected and for high risk groups resulted in an increase in condom use by both commercial sex workers and those reporting non-regular sexual partners. ${ }^{5}$

\section{ADAPTABLE APPLICATION}

A crucial factor in the ABC strategy's success is its broad applicability, and thus the ability to specifically and locally target sexual behaviour change. Rather than applying a unilateral approach to all populations, this strategy addresses the needs of high risk groups through the promotion of risk reduction in the form of barrier protection, while at the same time directly targeting other population groups and promoting sexual behaviour change in the form of risk avoidance. In Uganda, for example, there is strong evidence that programmes specifically promoting sexual deferral for adolescents and partner reduction for couples, changes conforming to traditional and cultural beliefs, ${ }^{7}$ substantially affected HIV incidence. ${ }^{58} 9$ The value of an HIV/AIDS prevention programme that can be adapted to the needs of specific groups and the limitations of an unilateral "condomcentric" approach to sexual behaviour change is highlighted by Dr David Wilson, a senior monitoring and education specialist for global HIV/AIDS: "As AIDS educators, we often publicly promote approaches that we would not countenance in our personal lives, such as the notion that it is acceptable for our spouses or children to have multiple partners, provided condoms are used."26 


\section{CONCLUSION}

While HIV/AIDS remains a complex epidemiological problem, which will require multifaceted initiatives aimed at issues ranging from the empowerment of women in developing nations to the needs of injecting drug users in North American cities, the Ugandan example suggests that broad based programmes focusing on sexual behaviour change can significantly affect population level HIV/AIDS rates. To do this, however, the pervasive problem of STDs must be openly tackled; direct recommendations for sexual behaviour change must include delayed sexual debut for adolescents, partner reduction, and risk reduction through barrier protection; and programmes must emphasise components of the original $\mathrm{ABC}$ strategy that are most appropriate for local settings and specific audiences.

Postgrad Med J 2005;81:615-617.

doi: 10.1136/pgmi.2005.034868

Correspondence to: Dr S Genuis, 2935-66 Street, Edmonton, Alberta, Canada, T6K 4Cl; sgenuis@ualberta.ca

Funding: none.

Conflicts of interest: none.

Dr Stephen John Genuis served as co-director of medical services at a hospital in Cameroon and is an associate professor at the University of Alberta. Shelagh K Genuis is a research librarian and writes on topics related to health promotion.

\section{REFERENCES}

1 World Health Organisation. The world health report 2004: changing history (overview). Geneva: WHO, 2004

2 Michaud CM, Murray CJ, Bloom BR. Burden of disease-implications for future research. JAMA 2001;285:535-9.

3 Anon. Uganda tackles AIDS from the very top down. AIDS Alert 1999;14(suppl 8):3-4.

4 Feuer C. Can PEPFAR save the most vulnerable? American Foundation for AIDS Research 2004:5:1-3.

5 Hogle J, Green EC, Nantulya V, et al. What happened in Uganda? Declining HIV prevalence, behavior change, and the national response. Washington, DC: US Agency for International Development, Office of HIV/AIDS, Bureau of Global Health, 2002. http://www.usaid.gov/ our_work/global_health/aids/Countries/africa/ uganda report.pdf

6 Piot P. Introduction. Br Med Bull 2001;58:3-5.

7 Museveni JK. Presentation at "Common Ground: A Shared Vision for Health" conference, Washington, DC, Jun 2004

8 Shelton AJ, Halperin DT, Nantulya V, et al. Partner reduction is crucial for balanced " $A B C$ " approach to HIV prevention. BMJ 2004;328:891-4.

9 Stoneburner RL, Low-Beer D. Population-level HIV declines and behavioral risk avoidance in Uganda. Science 2004;304:714-18.

10 Genuis SJ, Genuis SK. Primary prevention of sexually transmitted disease: applying the " $A B C$ " strategy. Postgrad Med J 2005;81:299-301.

11 Roehr B. Abstinence programmes do not reduce HIV prevalence in Uganda. BMJ 2005;330:496.

12 Brody S. Declining HIV rates in Uganda: due to cleaner needles, not abstinence or condoms. Int J STD AIDS 2004;15:440-1.

13 Parkhurst JO. The Ugandan success story? Evidence and claims of HIV-1 prevention. Lancet 2002:360:78-80

14 Hearst N, Chen S. Condom promotion for AIDS prevention in the developing world: is it working? Stud Fam Plann 2004;35:39-47.

15 Green EC, Conde A. Sexual partner reduction and HIV infection. Sex Transm Infect 2000;76: 145 .
16 Genuis SJ, Genuis SK. Managing the sexually transmitted disease pandemic: a time for reevaluation. Am J Obstet Gynecol 2004:191:1103-12.

17 Wawer MJ, Gray R, Serwadda D, et al. Declines in HIV prevalence in Uganda: not as simple as $A B C$. Twelfth conference on retroviruses and opportunistic infections, Boston, 2005: No 27LB

18 Schwartz LM, Woloshin S, Baczek L. Media coverage of scientific meetings: too much, too soon? JAMA 2002:287:2859-63.

19 Woloshin S, Schwartz LM. Press releases: translating research into news. JAMA 2002;287:2856-8

20 Shumaker SA, Legault C, Rapp SR, et al. Estrogen plus progestin and the incidence of dementia and mild cognitive impairment in postmenopausal women: the women's health initiative memory study: a randomized controlled trial. JAMA 2003;289:2651-62

21 Wassertheil-Smoller S, Hendrix SL, Limacher M, et al. Effect of estrogen plus progestin on stroke in postmenopausal women: the women's health initiative: a randomized trial. JAMA 2003;289:2673-84.

22 Bowser A. New WHI analysis: oral contraceptives may reduce CVD risk. Medscape Medical News. http://www.medscape.com/ viewarticle/491753?src = mp (accessed 6 Mar 2005).

23 National Institutes of Health Press Releases. Statement on oral contraceptive study from Barbara Alving, MD, Director of the Women's Health Initiative and Acting Director of the National Heart, Lung, and Blood Institute. http:// www.nih.gov/news/pr/dec2004/nhlbi-15.htm (accessed 6 Mar 2005).

24 Mitchell D. Condom use and deaths explain lower HIV prevalence in Rakai, Uganda. (MedScape from Web MD) http://www.medscape.com/ viewarticle/500121?src $=\mathrm{mp}$ (accessed $7 \mathrm{Mar}$ 2005)

25 Abraham P. Hooked on failure. World Magazine 2004; Nov 6. http://www.worldmag.com/ subscriber/displayarticle.cfm?id $=9851$ (accessed 8 Mar 2005).

26 Wilson D. Partner reduction and the prevention of HIV/AIDS. BMJ 2004;328:848-9.

\section{bmjupdates+}

bmjupdates+ is a unique and free alerting service, designed to keep you up to date with the medical literature that is truly important to your practice. bmjupdates+ will alert you to important new research and will provide you with the best new evidence concerning important advances in health care, tailored to your medical interests and time demands.

Where does the information come from?

bmiupdates+ applies an expert critical appraisal filter to over 100 top medical journals A panel of over 2000 physicians find the few 'must read' studies for each area of clinical interest

Sign up to receive your tailored email alerts, searching access and more...

www.bmjupdates.com 